\title{
Los trabajadores pobres y los bajos salarios en España: un análisis de los factores familiares $y$ laborales asociados a las distintas situaciones de pobreza
}

\author{
Isabel García Espejo y Marta IbáŃEz Pascual \\ Área de Sociología. Facultad de Ciencias Económicas \\ Universidad de Oviedo \\ igarcia@uniovi.es \\ mibanez@uniovi.es
}

Recibido: 11.10 .2007

Aceptado: 19.12.2007

\section{INTRODUCCIÓN}

En los últimos años en Europa se ha generado una nueva categoría social, los trabajadores pobres. Una categoría de análisis que aparece en Estados Unidos en los años 70 con el deseo de sacar a la luz pública la situación de aquellos hogares de trabajadores en los que, pese a la situación de empleo u ocupación de alguno de sus miembros, los ingresos familiares se encontraban por debajo del umbral de pobreza relativa.

La relación entre empleo y pobreza no se ha interpretado siempre de la misma forma. Por una parte, se ha considerado frecuentemente que ser trabajador pobre está íntimamente ligado a los empleos con salarios bajos; incluso algunas investigaciones señalan que las tasas de pobreza son más elevadas en aquellos países donde este tipo de empleos están más extendidos (Marx y Verbist, 1998). Se puede pensar, por tanto, que las políticas de empleo que incidan en la elevación de la cuantía de los salarios tendrán un efecto positivo en la re-

\footnotetext{
${ }^{1}$ Este artículo es uno de los productos del grupo de investigación sobre «Trabajadores pobres: empleos y hogares» creado en la Universidad de Oviedo en 2005. La investigación ha sido financiada por el «Plan Nacional de I+D+I» del Ministerio de Educación y Ciencia (Ref. SEJ20056485/SOCI) y dirigido por el Catedrático de Sociología Rodolfo Gutiérrez. Agradecemos a los evaluadores anónimos de este artículo sus recomendaciones, pues gracias a ellas ha ganado en claridad expositiva.
} 
ducción de la pobreza. Por el contrario, no es raro encontrarse con argumentos en defensa del aumento de los empleos con salarios bajos (y con acalorados debates sobre la generalización empírica de estos argumentos - Bazen, et al., 1998). Se entiende que el incremento de estos puestos de trabajo está asociado a la reducción del desempleo estructural de larga duración, que parece endémico en la zona europea, y a la disminución de la pobreza. La idea que se defiende es la de que Europa puede seguir el modelo de Estados Unidos, y en ciertos aspectos Reino Unido, donde se han generado empleos de baja calidad que han posibilitado la reducción del paro y la incorporación a la actividad laboral de ciertos grupos de población ${ }^{2}$.

Sin entrar en la polémica señalada, resulta evidente que la cuantía del salario y la calidad de los empleos son aspectos especialmente relevantes en la explicación de los niveles de pobreza de la población trabajadora. Ahora bien, en este artículo se considera que nos encontramos ante situaciones mucho más complejas de explicar, en las que intervienen otros factores de igual importancia que los ingresos individuales que habría que incorporar al análisis; en concreto nos referimos a la estructura de los hogares y al ciclo vital de la familia, ya que determinados eventos como tener hijos dependientes, vivir solo, o la ruptura de la unidad familiar pueden influir de manera significativa en el riesgo de pobreza de los trabajadores, con las implicaciones en política social que ello conlleva.

Este artículo parte de la premisa de que existen, pues, dos dimensiones en el análisis de la pobreza de los trabajadores: su salario y los ingresos y estructura de sus hogares. Salarios y hogares configuran dos situaciones de pobreza tipo: los asalariados con ingresos bajos y los trabajadores que viven en hogares pobres. La mayor parte de las investigaciones que han contemplado ambas dimensiones se han centrado en los individuos en los que coinciden las dos situaciones: salarios bajos y pobreza del hogar. En el presente artículo se pretende ir más allá y abordar, además de la citada situación, otras dos situaciones en las que también se tienen en cuenta la cuantía del salario y la estructura del hogar, y que podríamos denominar «de frontera»: la de aquellos trabajadores con salarios bajos pero cuyas características familiares les apartan de la pobreza; y la de aquellos otros que no teniendo salarios bajos las características familiares les hacen caer en la pobreza.

A partir de la citada tipología, el objetivo del artículo se centra en el análisis de los factores laborales y familiares que se hallan asociados a los distintos tipos de pobreza. Este análisis permitirá determinar cuáles son los grupos en el mercado de trabajo más vulnerables a sufrir cada uno de los riesgos de pobreza y de escasez de recursos considerados, así como las características familiares y laborales más relevantes de estos trabajadores pobres. Para llevar a cabo los objetivos propuestos se ha utilizado la Encuesta de Condiciones de Vida referida a España.

${ }^{2}$ Un segundo argumento en defensa del aumento de este tipo de empleos viene de la mano de las dificultades de Europa para competir en la economía global, se entiende que aumentando este tipo de empleos aumentará la competitividad de los mercados nacionales.

EMPIRIA. Revista de Metodología de Ciencias Sociales. N. ${ }^{\text {14 }}$, julio-dicembre, 2007, pp. 41-67. ISSN: $1139-5737$ 
La estructura de este artículo es la siguiente. En el primer apartado se exponen las aproximaciones teóricas y empíricas que han emprendido el estudio de la pobreza en los trabajadores. El apartado segundo está dedicado a la fuente de datos y a los indicadores utilizados para medir la pobreza del hogar y los bajos salarios. La descripción sociolaboral de los trabajadores pobres y de los perceptores de salarios bajos se presenta en el tercer apartado. El cuarto apartado está dedicado al análisis de los factores familiares y laborales asociados a los diferentes tipos de pobreza en los trabajadores. Finalmente en el quinto apartado se presentan las conclusiones más importantes del artículo.

\section{APROXIMACIONES TEÓRICAS Y EMPÍRICAS AL ESTUDIO DE LAS SITUACIONES DE POBREZA EN LOS TRABAJADORES}

Nos encontramos con dos grandes tradiciones de investigación en el estudio de la pobreza de los trabajadores. Por un lado la situación de los asalariados con trabajos en los que se reciben ingresos bajos, dominado por los economistas y los especialistas en el mercado de trabajo y las relaciones industriales. Y por otro, todo un campo de análisis sobre la pobreza en el hogar (incluidos los hogares de trabajadores), mucho más sociológico y mayoritariamente orientado a las políticas asistenciales del estado del bienestar. Para comprender mejor el fenómeno de los trabajadores pobres se han de recoger ambas tradiciones. Así, se hace imprescindible analizar las características de sus puestos de trabajo, pues se entiende que esta situación ha de correlacionar directamente con las situaciones de empleo de poca calidad, fundamentalmente por la baja cuantía de sus ingresos. Y se hace asimismo necesario ver su relación con los modelos de convivencia y la estructura familiar.

Si nos referimos a las situaciones de percepción de bajos salarios la literatura que aborda este tema se ha centrado en diversos factores que se encuentran asociados a una mayor o menor incidencia de los bajos salarios entre la población. Así, las características de los empleos constituyen variables que guardan relación con la incidencia de los bajos salarios, observándose una concentración de estos trabajadores en determinadas ocupaciones y ramas de actividad; en concreto en las ocupaciones manuales y en el sector servicios (Contini, Fillipi y Villosio, 1998; Arai, Asplund y Barth, 1998; Craypo y Cormier, 2000; Freeman y Schettkat, 2002). Asimismo se ha citado como un factor importante el tamaño de la empresa, de tal forma que los trabajadores que menos ingresos perciben son aquellos empleados en pequeñas empresas (Contini, Fillipi y Villosio, 1998).

Algunas características demográficas incrementan también la probabilidad de ocupar empleos de bajos salarios. Los jóvenes y las mujeres están mucho más representados en estos trabajos que los hombres y los trabajadores de mayor edad (Lucifora, 1998; Arai, Asplund y Barth, 1998; Freeman y Schettkat, 2002; Sloane y Theodossiou, 2002). En el caso de los jóvenes, un buen número de estos empleos constituyen una etapa inicial en su proceso de inserción laboral que 
conduce a otra etapa caracterizada por un significativo crecimiento salarial (Keese, Puymoyen y Swaim, 1998). Respecto a las mujeres, su mayor riesgo con relación a los hombres persiste después de controlar por diversos factores como la menor experiencia laboral y la composición del empleo por rama y ocupación (Keese, Puymoyen y Swaim, 1998). Por último, cabe citar los recursos personales de los trabajadores, fundamentalmente formativos. Así, cuanto mayor es el nivel educativo y la antigüedad y experiencia laboral del trabajador menor es la probabilidad de percibir bajos salarios (Sloane y Theodossiou, 2002).

Un elemento importante en el análisis de las situaciones y características de los trabajadores situados en los últimos lugares de la distribución salarial es determinar si esta situación constituye un fenómeno temporal en la vida laboral del trabajador, o por el contrario tiende a convertirse en un fenómeno permanente. Las teorías del mercado de trabajo dual sugieren que estas ocupaciones constituyen una «trampa» en el sentido de que no recompensan la inversión en capital humano y no conducen a la percepción de salarios más altos a lo largo del tiempo; un fenómeno que ha sido constatado por diversas investigaciones (Arai, Asplund y Barth, 1998; Eriksson, 1998; Sloane y Theodossiou, 2002). La situación tiende a ser más grave si se tiene en cuenta que estos trabajadores experimentan una mayor incidencia del paro, así como períodos de desempleo de larga duración. Su historia laboral suele caracterizarse por altos niveles de rotación laboral entre empleos de similares características con períodos intercalados de paro (Gregory y Jukes, 1998; Sloane y Theodossiou, 2002).

Por su parte, los estudios sobre trabajadores pobres se inician en Estados Unidos. Entre ellos merece la pena destacar el trabajo seminal de Levitan y otros (1987, nueva edición 1993) en el que se hace explícita esta «contradicción americana»: estar ocupado y a la vez ser pobre. Una contradicción de fuerte repercusión para la ideología política nacional pues destruye los cimientos del «sueño americano» desde el momento en el que la pobreza ya no se puede explicar por la pereza o la enfermedad, y nos encontramos con una amplia proporción de familias trabajadoras, que pese al esfuerzo laboral no superan el umbral de la pobreza.

En Europa la tradición sobre trabajadores pobres no es tan amplia. Un hito muy importante para su consolidación ha sido su aparición en las pautas europeas de empleo (European employment guidelines) aprobadas por la Comisión en 2003, en las que se utiliza como concepto operativo, planteándose como objetivo de la Comisión la reducción en Europa del número de trabajadores pobres. Hasta entonces, aunque tal concepto sí es utilizado, presenta graves dificultades de comparación, debido a la falta de unificación de indicadores ${ }^{3}$. En la actualidad, los estudios que permiten la comparación suelen estar bajo el paraguas de Eurostat y de los indicadores del Comité para la Protección Social (The Sub

${ }^{3}$ Otros autores ya han demostrado las dificultades para unificar las categorías de análisis en el fenómeno de los trabajadores pobres (Peña-Casas y Latta, 2004). Resulta especialmente relevante su repaso bibliográfico.

EMPIRIA. Revista de Metodología de Ciencias Sociales. N. ${ }^{14}$, julio-dicembre, 2007, pp. 41-67. ISSN: $1139-5737$ 
Group Indicator of the Social Protection Committe). Estas instituciones han desarrollado un indicador de trabajador pobre que se emplea en aquellos procesos europeos en el campo de la inclusión social sujetos al Método abierto de Coordinación (Open Method of Coordination).

Las investigaciones sobre trabajadores pobres ${ }^{4}$ destacan ciertas características laborales, a saber: salario bajo y mala calidad de los empleos, y ciertas características del hogar e individuales (Peña-Casas y Latta, 2004; Bardone y Guio, 2005). Por ejemplo, ser un trabajador pobre está íntimamente relacionado con obtener sueldos bajos, de forma que en la Europa de los trece y en 1995 un $37 \%$ de los trabajadores pobres tenían sueldos bajos. Además, estos trabajadores ocupan empleos de muy baja calidad, en los que el nivel de estudios exigido es mínimo, con una proporción mayor de mujeres autónomas, empleos más temporales y con gran rotación; en general feminizados y en mayor medida a tiempo parcial (Peña-Casas y Latta, 2004).

Respecto a las características del hogar, las investigaciones señalan que los más vulnerables son las familias monoparentales y aquellas en las que hay sólo un trabajador con niños dependientes. En general, parece que el talón de Aquiles es la intensidad laboral de la familia, es decir, la cantidad de trabajadores que hay en el hogar teniendo en cuenta el número de miembros, tanto adultos como menores (Peña-Casas y Latta, 2004; Bardone y Guio, 2005).

Algunos estudios que plantean la relación entre los trabajadores con salarios bajos y los asalariados que viven en hogar pobre se centran en el grado de solapamiento de estas dos realidades. Así, nos encontramos con que esta relación varía mucho según países y según se esté considerando la proporción de asalariados pobres con salarios bajos o viceversa, la proporción de asalariados con sueldos bajos que viven en hogares pobres. Por ejemplo, para datos de 1995, mientras que en Grecia y Reino Unido la proporción de empleados pobres que ganan poco es de 52 y $44 \%$ respectivamente, es decir, son situaciones enormemente relacionadas, en Dinamarca y Portugal no lo son tanto, pues su proporción es sólo del $21 \%$. Por otra parte, la proporción de los que ganan poco que son pobres presenta también cierta variabilidad, pasando del $13 \%$ en el caso de Dinamarca al 25\% en Italia (EIRO, 2002: 16-17). Esta investigación recopilatoria señala que los factores que previenen a los trabajadores con sueldo bajo de caer en la pobreza son mayoritariamente de dos tipos ${ }^{5}$ : por una parte, la presencia de más de un sueldo en el hogar; y, por la otra, las ayudas sociales, en general ayudas a la vivienda y al cuidado de los menores. En este sentido, un factor de los países del sur de Europa para alejar a los asalariados con ingresos bajos de la pobreza es el papel de la familia extensa, que puede prestar un importante apoyo en el cuidado de los niños o facilitar el acceso a la vivienda.

${ }^{4}$ Adelantando la definición, estamos considerando a aquellas personas mayores de 16 años que en el año de referencia hayan trabajado más de seis meses y no menos de 15 horas semanales y que convivan en hogares que se encuentran bajo el umbral de pobreza relativa.

5 A parte del efecto que en algunos países tiene la regulación por ley de un salario mínimo interprofesional.

EMPIRIA. Revista de Metodología de Ciencias Sociales. N. ${ }^{\circ}$ 14, julio-dicembre, 2007, pp. 41-67. ISSN: $1139-5737$ 
La investigación de Marx y Verbist (1998) señala cómo el nivel de vida de una familia depende fundamentalmente de la posición de cada uno de los miembros del hogar en el mercado de trabajo y no de la posición del cabeza de familia como ocurría hace décadas. Las familias de doble ingreso son las que menos probabilidad tienen de caer en la pobreza. Por el contrario, los niveles de pobreza entre las parejas con bajos salarios en las que solo un miembro tiene ingresos (el hombre) son considerablemente altos, sobre todo cuando hay niños. Cuando no hay niños dependientes estos niveles tienden a ser bastante menores. En la investigación también se constata cómo la mayor parte de los trabajadores que perciben bajos salarios viven en hogares en los que hay más de un miembro que aporta ingresos al hogar.

Una aportación original es la de Jane Millar y Karen Gardiner (Gardiner y Millar, 2006). Estas autoras empiezan observando las características familiares y de género de los trabajadores con salarios bajos, y, dentro de estos trabajadores, los que conviven en un hogar pobre (manteniendo el análisis por tipo de familia y género). Los resultados de estas autoras indican que la composición del hogar es un factor muy importante a la hora de explicar el riesgo de que los trabajadores con bajos salarios se encuentren en una situación de pobreza. La protección de la pobreza depende muy a menudo de vivir con otros individuos que pueden también aportar ingresos al hogar. Por ejemplo, los individuos solteros que no tienen personas dependientes a su cargo constituyen el mayor grupo entre los trabajadores con bajos salarios y tienen una dependencia mayor de los ingresos de otros adultos en el hogar, normalmente de sus padres. Los hombres tienen una capacidad mayor de evitar la pobreza debido a sus propios ingresos, mientras las mujeres se apoyan más en sus parejas. De las trabajadoras con bajos salarios, las madres que están solas son las que más probabilidades tienen de ser pobres. En esta investigación también se constata que las parejas con niños difieren mucho en su riesgo de pobreza, dependiendo de si es el hombre o la mujer el que percibe bajos ingresos. Los hombres tienen una probabilidad tres veces mayor de ser pobres que las mujeres en este grupo ${ }^{6}$.

\section{LOS DATOS Y MEDIDAS UTILIZADAS EN EL ESTUDIO}

\section{La encuesta de Condiciones de Vida}

Para llevar a cabo el análisis de las distintas situaciones de pobreza que se contemplan en este artículo, se ha utilizado como fuente de datos la Encuesta de Condiciones de Vida heredera del Panel de Hogares de la Unión Europea (PHOGUE). Esta encuesta, que comienza en 2004, pertenece al conjunto de operaciones estadísticas acordadas y armonizadas por los países de la Unión Europea,

${ }^{6}$ Pese a la riqueza explicativa de su estrategia de investigación, el uso de submuestras demasiado pequeñas reduce su fiabilidad.

EMPIRIA. Revista de Metodología de Ciencias Sociales. N. ${ }^{\text {14 }}$, julio-dicembre, 2007, pp. 41-67. ISSN: 1139-5737 
con el objetivo de disponer de una fuente de referencia sobre estadísticas comparables relativas a la distribución de ingresos y la exclusión social en el ámbito europeo (INE, 2004). La muestra está constituida por 15.000 viviendas distribuidas en 2.000 secciones censales de todo el territorio nacional español

\section{La medición de la pobreza en los trabajadores}

La pobreza en los trabajadores se puede definir en términos individuales y familiares. En el presente artículo se considera que ambas dimensiones lejos de ser excluyentes se han de analizar como complementarias, pero para poder observar su interrelación, antes se han de construir indicadores válidos para cada una de las dos dimensiones. Por una parte, se ha de tener en cuenta la pertenencia o no a un hogar pobre, y por otra, la cuantía del salario o ingresos.

Siguiendo las definiciones de Eurostat se ha determinado el concepto de hogar pobre, a la vez que se ha definido qué se entiende por trabajador. La definición de hogar pobre está tomada de la adoptada en la cumbre europea de Laeken de diciembre de 2001 (Dennis, 2002). Se entiende como hogar pobre aquel que se encuentra bajo el umbral de pobreza relativa. Se ha de distinguir entre el umbral de pobreza, expresado como ingreso equivalente de la persona, y el umbral de pobreza, expresado como ingreso total del hogar.

El valor del umbral de pobreza, expresado como ingreso equivalente de la persona, se fija en el $60 \%$ de la mediana de los ingresos por unidad de consumo de las personas 7 . Con la Encuesta de Condiciones de Vida de 2004 se establece en 6.278,7 euros. El valor del umbral de pobreza, expresado como ingreso total del hogar, el indicador que se emplea en la presente investigación, depende del número de unidades de consumo del hogar. Se obtiene multiplicando 6.278,7 por el número de unidades de consumo. Por ejemplo, para un hogar de un adulto el umbral es de 6.278,7 euros, para un hogar de dos adultos es de 9.418,1 euros (o 4.709 euros por persona), para un hogar de dos adultos y un menor de 14 años es de 11.301,7 euros (o 3.767,2 euros por persona), para un hogar de dos adultos y dos menores de 14 años es de 13.185,3 euros (o 3.296,3 euros por persona), etc.» $(\text { INE, 2005) })^{8}$.

\footnotetext{
${ }^{7}$ «Los ingresos por unidad de consumo del hogar se calculan para tener en cuenta economías de escala en los hogares. Se obtienen dividiendo los ingresos totales del hogar entre el número de unidades de consumo. Éstas se calculan utilizando la escala de la OCDE modificada, que concede un peso de 1 al primer adulto, un peso de 0,5 a los demás adultos y un peso de 0,3 a los menores de 14 años. Una vez calculado el ingreso por unidad de consumo del hogar se adjudica éste a cada uno de sus miembros. Estos ingresos por unidad de consumo de las personas (o ingreso equivalente de la persona) se utilizan en el cálculo de medidas de pobreza relativa». (INE, 2005).

${ }^{8}$ Con el objeto de analizar la pobreza en los hogares se está asumiendo que se produce un reparto equitativo dentro del hogar. Esta asunción es necesaria por fines operativos, aunque investigaciones cualitativas señalan desigualdades en el acceso a ciertos bienes dentro de las familias (Jenkins, 1991; Nolan, 2000; Jordan y Marx, 1992; Stocks et al. 2007).
} 
Con las dimensiones «ser trabajador» $\mathrm{y}$ «vivir en un hogar pobre» se construye el indicador «trabajador pobre», que en el presente estudio se llamará también «trabajador en hogar pobre» para resaltar el componente de convivencia que supone la situación de pobreza así precisada. La definición de trabajador pobre es la misma que la adoptada por la Unión Europea y Eurostat en el Open Method of Coordination (OMC) en el campo de la inclusión social y la Estrategia Europea para el Empleo (European Employment Strategy -EES). En principio se considera trabajador a los ocupados por cuenta propia y por cuenta ajena que han trabajado al menos siete meses en el año de referencia de la renta y al menos 15 horas a la semana en el empleo principal.

Al cruzar la variable que diferencia si el trabajador vive o no en un hogar pobre con la situación laboral del trabajador (empleador, autónomo, asalariado y ayuda familiar) se observa la gran proporción de trabajadores por cuenta propia que viven en hogares pobres.

Tabla 1. Trabajadores pobres según su situación profesional (porcentajes)

\begin{tabular}{lcccc}
\hline & \multicolumn{2}{c}{ Trabajadores pobres } & & \\
Situación profesional & NO & SÍ & Total & Total ponderado \\
\hline Empleador & 69,5 & 30,5 & 100,0 & 692.516 \\
Autónomo & 67,6 & 32,4 & 100,0 & 1.673 .917 \\
Ayuda familiar & 64,0 & 36,0 & 100,0 & 64.160 \\
Asalariado & 92,9 & 7,1 & 100,0 & 14.161 .950 \\
Total & 89,2 & 10,8 & 100,0 & 16.592 .543 \\
\hline
\end{tabular}

FUENTE: ECV-2004. España.

Este resultado nos lleva a considerar la conveniencia de centrar el análisis únicamente en los asalariados, por diferentes razones: en primer lugar por la existencia de ingresos negativos (deudas) entre los empresarios y autónomos (¿son pobres los que deben mucho?); en segundo lugar por las dudas sobre la fiabilidad de los ingresos declarados en encuestas por parte de los trabajadores por cuenta propia. En suma, en la presente investigación se trabajará con la submuestra de los asalariados.

En el caso de la segunda dimensión de la pobreza, la que tiene en cuenta el salario del trabajador sin considerar la estructura del hogar, el indicador utilizado recoge la cuantía del salario/hora. La utilización del salario/hora permite neutralizar la influencia del tiempo de trabajo realizado cuando se considera al grupo de asalariados con ingresos bajos. Neutralizar la influencia del tiempo de trabajo permite que ya no se tengan en cuenta como trabajadores con salarios bajos a aquellos que están a tiempo parcial, pues parece razonable que si no se trabaja un número de horas relevante los ingresos sean escasos. Para hallar el sa- 
lario/hora se han seguido las indicaciones del instituto español de estadística (INE) con relación a las variables que figuran en la ECV:

$$
\text { salhora }=\text { PY200G/(PL060*4) }
$$

en el que:

PY200G es el salario bruto mensual actual del empleo principal.

PL060 es el número de horas semanales dedicadas a ese trabajo principal.

Se entiende por salario bajo a los asalariados con un salario/hora inferior al $60 \%$ de la mediana del salario/hora de la población asalariada ${ }^{9}$. En España la mediana del salario/hora es $7 €$ con lo que el umbral para considerar un salario/hora bajo (menos del $60 \%$ de la mediana) es $4,2 €$.

\section{DESCRIPCIÓN DE LA DISTRIBUCIÓN SOCIOLABORAL DE LAS SITUACIONES DE POBREZA}

Antes de profundizar en el análisis de los factores familiares y laborales que se encuentran asociados a los tipos de situaciones de pobreza establecidas en este artículo, resulta ilustrativo tener una visión general de las características familiares y laborales de los adultos que viven en hogares pobres, de los asalariados en tales hogares y las de aquellos cuyo salario/hora se encuentra por debajo del $60 \%$ de la mediana (ver Tabla 1).

Como no podría ser de otra manera, el porcentaje de personas que viven en hogares por debajo del umbral de pobreza relativa es mucho más alto cuando tenemos en cuenta a toda la población mayor de quince años, que cuando sólo analizamos asalariados. Si sólo se considera a los asalariados, el porcentaje de trabajadores que viven en hogares pobres disminuye considerablemente, llegando a $7,1 \%$. Sin embargo, el perfil de estos asalariados varía considerablemente según se tenga en cuenta una u otra de las situaciones de riesgo de pobreza antes señaladas (riesgo de pobreza doméstica o por ingresos propios).

Ya en una primera aproximación se observa que la obtención de un salario/hora bajo y la pobreza son situaciones analíticamente distintas. Mientras que la percepción de un salario bajo está asociado mayoritariamente a características personales como el sexo y la edad y a las características productivas del puesto de trabajo (rama de actividad, tipo de contrato, ...), que un asalariado conviva en una familia que se encuentre bajo el umbral de riesgo de pobreza, es decir, la situación de «asalariado pobre» está mucho más asociado a las características del hogar.

El sexo sigue segmentando los mercados laborales. El salario medio por hora de los varones es un 17,3\% más alto que el de las mujeres (INE, 2005) y con los datos de la ECV un $14,2 \%$ de las mujeres cobran salarios hora por debajo del $60 \%$ de la mediana. Sin embargo, esta situación no debe estar asociada directamente a la pobreza (sólo un 5,9\% de las mujeres son asalariadas en hogares pobres) pues

\footnotetext{
${ }^{9}$ Este mismo indicador es el utilizado por Gardiner y Millar (2006).
} 
Tabla 2a. Variables sociodemográficas y familiares en las situaciones de riesgo de pobreza. Porcentajes en cada una de las situaciones

\begin{tabular}{lccc}
\hline & $\begin{array}{c}\text { De adultos } \\
\text { (>de 15 años) } \\
\text { en hogares pobres }\end{array}$ & $\begin{array}{c}\text { De asalariados } \\
\text { en hogares } \\
\text { pobres }\end{array}$ & $\begin{array}{c}\text { De asalariados } \\
\text { con salario/hora } \\
\text { bajo }\end{array}$ \\
\hline TOTAL & 20,4 & 7,1 & 9,5 \\
Varones & 19,0 & 7,9 & 6,6 \\
Mujeres & 21,8 & 5,9 & 14,2 \\
Por grupos de edad & - & & \\
- hasta 15 años & 19,1 & 14,1 & 55,4 \\
- de 16 a 24 años & 17,2 & 6,7 & 23,5 \\
- de 25 a 54 años & 26,4 & 7,3 & 8,0 \\
- más de 54 años & 37,4 & 5,7 & 7,5 \\
Por tipo de convivencia & 36,7 & 5,7 & 9,8 \\
- Vive solo/a & 21,8 & 12,3 & 5,4 \\
- Un adulto/a con menor/es & 20,0 & 3,0 & 8,0 \\
- Dos adultos solos & 14,2 & 10,1 & 5,9 \\
- Dos adultos con menor/es & 26,0 & 4,8 & 12,0 \\
- Más de dos adultos sin menores & 14,4 & 13,4 \\
- Más de dos adultos con menor/es & & & - \\
Intensidad Laboral ${ }^{10}$ & 44,0 & - & 6,4 \\
- 0 & 30,4 & 23,8 & 8,0 \\
- de 0,02 a 0,49 & 15,7 & 15,0 & \\
- 0,5 - & 6,8 & 5,9 & \\
- de 0,51 a 0,99 & 2,7 & 2,3 & \\
- 1 & & & \\
\hline
\end{tabular}

FUENTE: ECV-2004. España.

aquellas trabajadoras que conviven en pareja (la situación más frecuente) lo hacen mayoritariamente con un trabajador, y las parejas de doble ingreso tienen muy pocas probabilidades de estar bajo el umbral de riesgo de pobreza.

La juventud también esta asociada a la aceptación de empleos de baja calidad: el 23,5\% de los jóvenes entre 16 y 24 años tienen salarios hora bajos. La explicación puede ser doble, por una parte porque está socialmente asumido que en los primeros momentos de la carrera laboral se van a obtener ingresos menores y a medida que aumente la experiencia laboral estos ingresos aumentarán. Por otra parte, el aumento de la desregularización de las condiciones laborales hace que las personas que están ingresando en el mercado de trabajo en los últimos años, mayoritariamente jóvenes, sean los que sufren en mayor medida esta nueva segmentación. Sin entrar en la veracidad de ambas afirmaciones, los menores ingresos de los jóvenes se asumen socialmente en nuestro país, de forma que es común que la emancipación juvenil del hogar familiar se produzca en la trein-

\footnotetext{
${ }^{10}$ Este mismo indicador se emplea en Bardote y Guio (2005) y se explica con detalle en el apartado siguiente.
} 
tena, y que mientras tanto el/la joven viva con sus padres, de ahí que la proporción de jóvenes trabajadores que viven en hogares pobres es menor a la media.

Como se señalaba anteriormente, las dimensiones más explicativas a la hora de entender por qué los ingresos anuales del hogar se encuentran por debajo del umbral de la línea de pobreza relativa son las características del hogar, en concreto: la intensidad laboral y el número de dependientes. Difícilmente podría ser de otra manera, pues esta relación es producto de la propia elaboración de las variables dependientes. En el salario/hora bajo nuestra unidad de análisis es el individuo, por lo que será una realidad explicada por características individuales y laborales. La pobreza es un fenómeno que se entiende familiar, por lo que la unidad de análisis es la unidad doméstica y es su estructura la que nos aporta las claves del fenómeno.

Los asalariados que viven en hogares por debajo del umbral de pobreza aparecen en mayor proporción en las familias con hijos menores, especialmente en las monoparentales $(12,3 \%)$ y cuando el asalariado convive en un hogar en el que hay más de dos adultos con uno o más menores. Este último caso suele ser el de una familia nuclear en la que el hijo mayor ha superado la edad de 15 años pero sigue estudiando. Esta puede ser la razón por la que también se observa una mayor proporción de asalariados con ingresos bajos en este tipo de convivencia.

La intensidad laboral del hogar parece el indicador más fiable a la hora de entender las probabilidades de que un asalariado viva en un hogar pobre. Como se aprecia en la tabla adjunta, la proporción de estos trabajadores va disminuyendo a medida que aumenta la intensidad laboral, hasta llegar al 2,3\% cuando la intensidad laboral del hogar es la máxima. Esta relación no es directa en el caso de los asalariados con ingresos hora bajos, pues, aunque la mayor proporción de estos asalariados conviven en familias con poca intensidad laboral, nos encontramos con que la menor proporción $(6,4 \%)$ se encuentra en aquellas familias en las que trabaja la mitad de las personas que pueden hacerlo. Éstas pueden ser familias de sólo dos miembros, en las que los altos ingresos del varón desmotivan la oferta de trabajo de la pareja.

Si nos referimos ahora a la distribución de los asalariados en hogares pobres y de los asalariados que perciben un salario/hora bajo según las principales características de los empleos, lo primero que salta a la vista en ambos casos es su concentración en determinadas ocupaciones y ramas de actividad, si bien la concentración es mayor en el caso de los asalariados con sueldos bajos, lo que sugiere un mayor poder explicativo de las variables laborales cuando se atiende al salario que cuando se contempla la naturaleza pobre o no pobre del hogar.

La pobreza del hogar es más alta en los trabajadores manuales, sobre todo en los trabajadores cualificados de la agricultura y en los trabajadores no cualificados. Que el hogar de estos trabajadores sea pobre puede ser debido a que tales categorías suelen estar relacionadas con empleos que ofrecen sueldos bajos, así como con ciertos modelos de familia con baja intensidad laboral. Nos referimos a familias en los que ambos cónyuges tienen escasos recursos formativos y sólo un miembro de la pareja (el varón) trabaja, sobre todo si hay hijos menores, ya que el sueldo que puede lograr la mujer es asimismo bajo y no compen- 
Tabla 2b. Variables laborales en las situaciones de riesgo de pobreza

\begin{tabular}{|c|c|c|}
\hline & $\begin{array}{c}\text { De asalariados } \\
\text { en hogares } \\
\text { pobres }\end{array}$ & $\begin{array}{l}\text { De asalariados } \\
\text { con sueldo } \\
\text { bajo }\end{array}$ \\
\hline \multicolumn{3}{|l|}{ Por categoría ocupacional } \\
\hline $\begin{array}{l}\text { - Ejecutivos } \\
\text { - Técnicos y Profesionales } \\
\text { - Técnicos de Apoyo } \\
\text { - Empleados administrativo } \\
\text { - Trabajadores de los servicios } \\
\text { - Trabajadores cualificados de la agricultura } \\
\text { - Trabajadores cualificados de la industria } \\
\text { - Operadores, montadores } \\
\text { - Trabajadores no cualificados } \\
\text { - FFAA }\end{array}$ & $\begin{array}{r}0,6 \\
1,6 \\
2,7 \\
3,1 \\
9,9 \\
17,7 \\
9,7 \\
7,6 \\
13,4 \\
0,1\end{array}$ & $\begin{array}{r}2,3 \\
1,1 \\
2,0 \\
6,7 \\
19,6 \\
20,9 \\
7,2 \\
8,0 \\
21,3 \\
9,2\end{array}$ \\
\hline \multicolumn{3}{|l|}{ Por rama de actividad (NACE) } \\
\hline $\begin{array}{l}\text { - Agricultura, ganadería y pesca }(\mathrm{a}+\mathrm{b}) \\
\text { - Industria }(\mathrm{c}+\mathrm{d}+\mathrm{e}) \\
\text { - Construcción (f) } \\
\text { - Comercio (g) } \\
\text { - Hotelería (h) } \\
\text { - Transporte y comunicaciones (i) } \\
\text { - Intermediación financiera (j) } \\
\text { - Act. Inmobiliarias; serv empresariales (k) } \\
\text { - admón.. Pública (l) } \\
\text { - Educación (m) } \\
\text { - Actividades sanitarias y Servicios sociales (n) } \\
\text { - Servicios personales y de limpieza }(\mathrm{o}+\mathrm{p}+\mathrm{q})\end{array}$ & $\begin{array}{r}22,1 \\
4,7 \\
11,7 \\
7,2 \\
12,2 \\
5,7 \\
0,9 \\
4,5 \\
3,4 \\
4,0 \\
2,5 \\
11,6\end{array}$ & $\begin{array}{r}26,0 \\
6,9 \\
6,4 \\
18,2 \\
17,3 \\
6,8 \\
1,3 \\
9,5 \\
1,6 \\
1,8 \\
6,6 \\
27,2\end{array}$ \\
\hline \multicolumn{3}{|l|}{ Por tamaño del centro de trabajo } \\
\hline $\begin{array}{l}\text { - Una persona } \\
\text { - de } 2 \text { a } 5 \\
\text { - de } 6 \text { a } 10 \\
\text { - de } 11 \text { a } 19 \\
\text { - de } 20 \text { a } 49 \\
\text { - más de } 49 \text { personas } \\
\text { - no sabe pero más de } 10 \\
\text { - ns-nc }\end{array}$ & $\begin{array}{r}18,9 \\
11,0 \\
8,4 \\
7,7 \\
5,8 \\
2,8 \\
10,6 \\
11,8\end{array}$ & $\begin{array}{r}36,9 \\
21,0 \\
12,3 \\
8,4 \\
5,5 \\
4,2 \\
8,3 \\
9,8\end{array}$ \\
\hline \multicolumn{3}{|l|}{ Por tipo de contrato } \\
\hline $\begin{array}{l}\text { - Fijo } \\
\text { - Temporal }\end{array}$ & $\begin{array}{r}5,1 \\
12,9\end{array}$ & $\begin{array}{r}7,4 \\
16,6\end{array}$ \\
\hline TOTAL PONDERADO & 14.161 .950 & 12.031 .321 \\
\hline
\end{tabular}

EMPIRIA. Revista de Metodología de Ciencias Sociales. N. ${ }^{\circ}$ 14, julio-dicembre, 2007, pp. 41-67. ISSN: $1139-5737$ 
sa los gastos de cuidado. Por su parte, los bajos salarios son característicos de los trabajadores no cualificados, de los trabajadores cualificados de la agricultura y de los trabajadores de los servicios. En muchos casos el tipo de empleos a los que hacen referencia estas categorías requieren pocas cualificaciones y no suelen ofrecer oportunidades de carrera laboral a medio y largo plazo.

Respecto a la rama de actividad, en ambos casos destaca el elevado porcentaje de la rama de agricultura, ganadería y pesca. La proporción de hogares pobres es asimismo superior en las ramas de hostelería y de servicios personales y limpieza; ramas caracterizadas en España por una alta temporalidad de los empleos y una acusada rotación laboral. Estas mismas actividades destacan en la distribución de los bajos salarios pero con porcentajes más elevados, y a ellas hay que añadir la rama del comercio.

Otras características de los empleos resultan relevantes en la distribución de la pobreza entre los asalariados. La concentración de los hogares pobres y de los bajos salarios en las empresas de menor tamaño es abrumadora, sobre todo en la segunda situación. Así, cerca del 30\% de los asalariados que viven en un hogar pobre trabajan en empresas de menos de cinco trabajadores, y el porcentaje alcanza el 57,9\% en el caso de los asalariados con bajos ingresos. Finalmente, la temporalidad de los empleos es otra característica de ambas situaciones.

\section{FACTORES FAMILIARES Y LABORALES ASOCIADOS A LOS DIFERENTES TIPOS DE POBREZA EN LOS TRABAJADORES}

En este apartado se analizan con mayor profundidad los factores familiares y laborales asociados a las distintas situaciones de pobreza en los trabajadores. El establecimiento de tales situaciones parte de la interrelación entre las dos dimensiones de la pobreza que hemos visto hasta ahora: asalariado en hogar pobre y asalariado con salario bajo. El cruce de ambas variables figura en el siguiente cuadro:

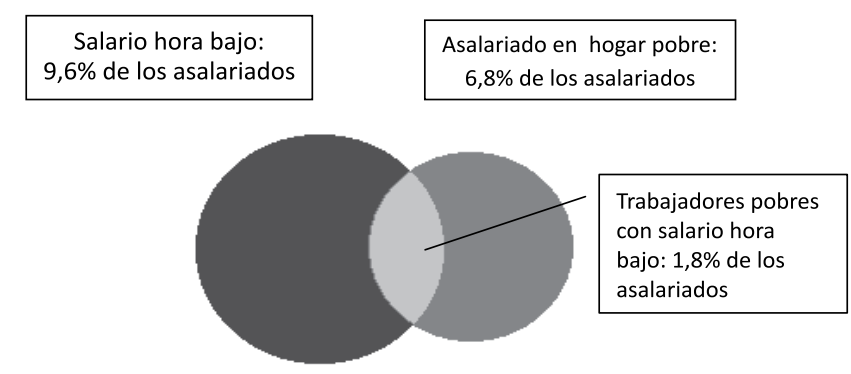

De todos los "Salario hora bajo":

- $18,3 \%$ viven en hogar pobre

De todos los asalariados pobres:

- $25,7 \%$ tienen salario bajo

- $81,7 \%$ viven en hogar NO pobre

- $74,3 \%$ NO tienen salario bajo

Gráfico 1. Interrelación de las distintas situaciones de pobreza 
Como puede observarse, no siempre coincide tener un salario/hora bajo con vivir en un hogar pobre. En el caso español, del 9,6\% de los asalariados cuyo salario/hora es inferior al $60 \%$ de la mediana del salario/hora general sólo viven en un hogar pobre el 18,3\%. Por su parte, un 6,8\% de los asalariados viven en hogares pobres, de los cuales el $25,7 \%$ tienen salarios bajos. (Este dato contrasta con el $37 \%$ de la Europa de los 13 -Peña-Casas y Latta, 2004). En otras palabras, la mayoría de los que tienen un salario bajo no son pobres pues sus hogares no lo son (el $81,7 \%$ ); y la mayoría de los asalariados que viven en hogares pobres no tienen salarios bajos, el 74,3\% ${ }^{11}$.

Las diferentes realidades que se han puesto de manifiesto con los datos expuestos nos llevan a establecer la siguiente tipología de situaciones de pobreza en los trabajadores asalariados:

- Asalariados que viven en hogar pobre y que perciben un salario/hora bajo. En los modelos esta situación se llama «pobreza más grave», pues tanto la calidad del empleo como las características del hogar avocan al trabajador a una situación de alto riesgo ${ }^{12}$.

- Asalariados que perciben un salario/hora bajo y que, sin embargo pertenecen a un hogar que no es pobre. Es decir, las características de su familia son las que le alejan de la situación de riesgo.

- Asalariados que no perciben un salario/hora bajo y que sin embargo conviven en un hogar pobre. Recoge aquellas situaciones en las que pese a que la calidad del empleo es buena, son las características familiares las que avocan a la pobreza.

Se va a recurrir a distintos modelos de regresión logística, en los que las variables dependientes son cada una de las distintas situaciones de pobreza señaladas ${ }^{13}$. En concreto, se aplicarán regresiones logísticas multinomiales, en las que el valor de comparación «0» serán los casos que no padecen ninguna situación de pobreza (8.264 casos, que ponderados ascienden a 8.264.463 y que constituyen el $93,2 \%$ de la muestra), que se opondrá sucesivamente, primero a aquellas situaciones que hemos denominado pobreza más grave (183 casos, ponderados 170.359 , un 1,8\% de la muestra); segundo las situaciones de salario/hora bajo en

${ }^{11}$ Los porcentajes pueden variar unas décimas según la muestra que se emplee, pues en aquellos casos en los que se relaciona la situación de pobreza en el hogar con los ingresos por hora aumentan los casos perdidos.

${ }^{12}$ Esto no significa que se minusvalore la gravedad de otras situaciones de pobreza; por ejemplo, es difícil decir qué situación es más grave, si la de un joven que vive sólo, acaba de empezar a trabajar y gana un sueldo muy bajo, o la de un hogar compuesto por un adulto con un sueldo que no es bajo pero con menores a su cargo.

${ }_{13}$ Al relacionar las distintas situaciones de pobreza, el tamaño de la muestra se ha visto disminuido. En concreto estamos trabajando con aquellos asalariados que han trabajado más de seis meses en el año de referencia y más de 15 horas a la semana y para los que hay información sobre el salario bruto mensual actual del empleo principal y el número de horas semanales dedicadas a ese trabajo principal. En total 9.752 casos y 12.031 .321 si se pondera la muestra. 
hogar no pobre (552 casos, ponderados 758.269 , un 7,8\%); y tercero las situaciones de salario/hora no bajo en hogar pobre ( 753 casos, ponderados 492.709 , un $5,1 \%$ de la muestra).

Conviene precisar que en este artículo no se pretende la cuantificación de probabilidades. La intención de la construcción del modelo se ha centrado en el análisis de la «correlación o «asociación» de las variables que se han considerado relevantes 14 .

Las variables independientes incluidas en los modelos han sido: variables sociodemográficas (sexo, edad, nacionalidad, comunidad autónoma y tamaño de hábitat), variables que recogen ciertas características del hogar (tipo de convivencia, intensidad laboral del hogar, cuidado de los hijos), variables relativas a los recursos formativos de los individuos (si el trabajador está estudiando en el momento de la encuesta, nivel de estudios finalizado), variables que recogen las condiciones laborales del trabajador en el empleo actual o en el último si está en paro en el momento de la encuesta (categoría laboral, rama de actividad, funciones directivas del trabajo, tipo de contrato, tamaño de la empresa, número de horas trabajadas a la semana) variables que hacen referencia a la historia laboral del trabajador (número de años en trabajo remunerado, edad a la que se empezó a trabajar, si se ha cambiado de trabajo en el año de la renta, número de meses no ocupado en el año de la renta). La definición de aquellas variables que han necesitado una construcción más minuciosa se expone a continuación.

Tipo de convivencia. Relaciona el número de personas adultas y de menores en el hogar. La presencia de dependientes permite observar el momento del ciclo vital familiar, con lo que se incorpora al análisis cierta perspectivą dinámica muy necesaria en el análisis de las situaciones de riesgo de pobreza ${ }^{15}$.

Intensidad laboral del hogar. Para elaborar la intensidad laboral del hogar se ha adoptado el indicador de Eurostat (2005). Se seleccionan primero a aquellas personas consideradas en edad laboral. Personas en edad laboral: aquellas que se encuentran entre 16 y 64 años, a excepción de los individuos que teniendo de

${ }^{14}$ En los modelos de regresión logística se ha aplicado el método de selección de variables denominado Adelante: $R V$ o de incorporación progresiva de las variables independientes (dentro del paquete estadístico SPSS) que consiste en ir añadiendo los posibles predoctores o variables independientes de una en una, manteniendo en los modelos las que son estadísticamente significativas y descartando las que no lo son. El criterio de significación estadística es el 95,5\%. Por otra parte, en el uso de variables explicativas categóricas es necesaria la utilización de un término independiente que no aparezca en el modelo. En este caso se ha optado por el contraste de desviación del efecto general, que consiste en la comparación de cada una de las categorías de la variable independiente (excepto la que se ha omitido) con el efecto total. Se ha optado por este contraste frente al Simple (cada categoría de la variable independiente, excepto la propia categoría de referencia, se compara con la categoría de referencia) dado que no se persigue el cálculo de probabilidades.

${ }^{15} \mathrm{El}$ análisis dinámico nos demuestra que el porcentaje de familias que se mantienen a lo largo de los años bajo el umbral de riesgo de pobreza es distinto según países y características familiares (Whelan et al., 2000; Layte and Whelan, 2003). Se entiende que una de las características familiares más importantes a la hora de conducir al hogar a la pobreza será el momento del ciclo vital familiar, especialmente la presencia de menores dependientes.

EMPIRIA. Revista de Metodología de Ciencias Sociales. N. ${ }^{\circ}$ 14, julio-dicembre, 2007, pp. 41-67. ISSN: $1139-5737$ 
16 a 24 son inactivos y conviven con alguno de sus progenitores. Se calcula dividiendo la suma de todos los meses trabajados por los miembros del hogar en edad de trabajar por el número de miembros en edad de trabajar multiplicado a su vez por el número de meses potencialmente trabajables (12 cada miembro). El rango de este indicador es de 0 a 1 , siendo 0 aquellos individuos que viven en hogares en los que ningún miembro en edad laboral ha trabajado y 1 cuando todos los miembros en edad laboral han trabajado los 12 meses del año de referencia. No tienen valores en esta variable aquellas personas que viven en hogares en los que no hay nadie en edad de trabajar. Se excluyen los hogares compuestos únicamente por estudiantes.

Cuidado de los hijos. Esta variable se calcula restando al número total de horas semanales que se supone se necesita para el cuidado de los hijos (168h) la suma de las horas semanales que los menores de 13 años pasan fuera del hogar en instituciones de cuidado y/o educativas, así como las horas que permanecen en casa atendidos por cuidadores profesionales y/o otras personas sin remunerar (abuelos, parientes, amigos, ...). En los hogares en los que hay más de un menor de 13 años, se suman las horas de cada uno y se dividen por el número de menores. Tal variable se entiende como una buena medida del trabajo doméstico.

Para abordar el análisis se han considerado diferentes hipótesis, ordenadas a partir de los tres tipos de pobreza señalados: la pobreza más grave, y aquellas situaciones «de frontera»: el caso de los asalariados que viviendo en hogares cuyos ingresos se encuentran por debajo del umbral de pobreza tienen salarios más altos, y el de aquellos que teniendo salarios bajos no viven en hogares pobres.

Como ya se ha señalado anteriormente, las características de los empleos y los recursos formativos del trabajador van a ser variables especialmente relevantes en la explicación de la situación de percepción de bajos salarios. Que un asalariado conviva en una familia que se encuentre bajo el umbral de riesgo de pobreza, es decir, la situación de «asalariado pobre» va a responder más a variables relativas al hogar que a las propiamente laborales.

¿Cuáles son las características de la situación de pobreza más grave, en la que coincide el salario bajo y el hogar pobre? La literatura refleja dos perfiles sociales muy concretos. El primero sería el hogar en el que sólo el varón cabeza de familia trabaja de manera remunerada a tiempo completo, especialmente si hay niños en el hogar. En este tipo de hogar en el que el único sustentador percibe un salario bajo, los niveles de estudios de ambos cónyuges se espera que sean escasos, de acuerdo con la tendencia a la homogamia educativa entre las parejas (Carabaña, 1994). En esta situación, sobre todo si hay niños pequeños, a la familia no le interesa que la mujer trabaje fuera del hogar, pues su bajo sueldo en el mercado no compensa los gastos de cuidado en los que incurre la familia. En otras palabras, las posibilidades del hogar de ofertar trabajo se supone que son inversamente proporcionales a las necesidades del trabajo de cuidado, especialmente cuando el escaso monto del «segundo sueldo» va a desincentivar la participación de la mujer/madre. Como se aprecia, la construcción de las parejas produce «reforzamiento de clase» y constituye un efecto de «atrapamiento» en la pobreza. 
Tabla 3. Regresiones LOGIT. Relación de las variables sociodemográficas, familiares y laborales con las situaciones de pobreza

\begin{tabular}{|c|c|c|c|}
\hline & $\begin{array}{c}\text { Pobreza } \\
\text { más grave } \\
\text { Coef. BETA }\end{array}$ & $\begin{array}{c}\text { Salario/ } \\
\text { hora bajo } \\
\text { Coef. BETA }\end{array}$ & $\begin{array}{c}\text { Pobre } \\
\text { por hogar } \\
\text { Coef. BETA }\end{array}$ \\
\hline Año de nacimiento & & & $-0,022 * * *$ \\
\hline Varón (Ref. mujer) & $-0,477 * * *$ & $-0,669 * * *$ & \\
\hline $\begin{array}{l}\text { Nacionalidad (Ref. Resto del mundo) } \\
\text { - Española } \\
\text { - UE24 } \\
\text { - Resto de Europa }\end{array}$ & $\begin{array}{r}* * \\
-0,094 \\
0,016 \\
-0,867\end{array}$ & & $\begin{array}{r}* * * \\
-1,152 * * * \\
0,120 \\
0,531\end{array}$ \\
\hline $\begin{array}{l}\text { Tipo de convivencia } \\
\text { (Ref. Más de dos adultos con menor/es) } \\
\text { - Vive solo/a } \\
\text { - Un adulto/a con menor/es } \\
\text { - Dos adultos solos } \\
\text { - Dos adultos con menor/es } \\
\text { - Más de dos adultos sin menores }\end{array}$ & $\begin{array}{r}* * * \\
0,166 \\
2,309 * * * \\
-1,232 * * * \\
-0,294 \\
-1,271 * * *\end{array}$ & $\begin{array}{r}* * * \\
0,194 \\
-1,808 * * \\
0,385 * \\
0,076 \\
0,675^{* * *}\end{array}$ & $\begin{array}{r}* * * \\
0,690 * * \\
1,238 * * * \\
-1,041 * * * \\
0,312 * * \\
-1,220 * * *\end{array}$ \\
\hline $\begin{array}{l}\text { Intensidad Laboral } \\
\text { Cuidado de menores en el hogar }\end{array}$ & $\begin{array}{r}-4,220 * * * \\
-0,004 * *\end{array}$ & & $-5,614 * * *$ \\
\hline $\begin{array}{l}\text { Está estudiando (Ref No está estudiando.) } \\
\text { - Primaria } \\
\text { - ESO } \\
\text { - Secundaria de } 2 .^{\text {a etapa }} \\
\text { - FP de } 2 .^{\mathrm{a}} \text { etapa } \\
\text { - Educación superior }\end{array}$ & $\begin{array}{r}* * * \\
4,531 \\
4,349 \\
-15,722 \\
4,841 \\
1,103\end{array}$ & $\begin{array}{r}* \\
3,736 \\
4,119 \\
3,168 \\
-15,710 \\
2,103\end{array}$ & \\
\hline $\begin{array}{l}\text { Nivel educativo (Ref. Primaria) } \\
\text { - ESO } \\
\text { - Secundaria de } 2 .^{\text {a }} \text { etapa } \\
\text { - FP superior } \\
\text { - Superior }\end{array}$ & & $\begin{array}{r}* * * \\
-0,139 \\
-0,178 \\
0,821 \\
-0,768 * * *\end{array}$ & $\begin{array}{r}* * * \\
4,006 \\
3,606 \\
-14,925 \\
3,239\end{array}$ \\
\hline $\begin{array}{l}\text { Categoría ocupacional (Ref. FFAA) } \\
\text { - Ejecutivos y empresarios } \\
\text { - Técnicos y Profesionales } \\
\text { - Técnicos de Apoyo } \\
\text { - Empleados administrativo } \\
\text { - Trabajadores de los servicios } \\
\text { - Trabajadores cualificados de la agricultura } \\
\text { - Trabajadores cualificados de la industria } \\
\text { - Operadores, montadores } \\
\text { - Trabajadores no cualificados }\end{array}$ & $\begin{array}{r}* * * \\
1,159 \\
-0,097 \\
0,534 \\
0,412 \\
2,130 \\
2,632 \\
1,762 \\
1,963 \\
2,434\end{array}$ & $\begin{array}{r}* * * \\
-0,005 \\
-1,581 * * * \\
-0,707 * * * \\
-0,176 \\
0,261 * \\
0,484 \\
0,192 \\
-0,030 \\
0,633 * * *\end{array}$ & $\begin{array}{r}* * * \\
-15,589 \\
1,176 \\
1,516 \\
1,739 \\
2,034 \\
2,394 \\
2,174 \\
2,096 \\
2,075\end{array}$ \\
\hline $\begin{array}{l}\text { Rama de actividad (NACE) (Ref. NS-NC) } \\
\text { - Agricultura, ganadería y pesca }(\mathrm{a}+\mathrm{b}) \\
\text { - Industria }(\mathrm{c}+\mathrm{d}+\mathrm{e}) \\
\text { - Construcción }(\mathrm{f}) \\
\text { - Comercio }(\mathrm{g}) \\
\text { - Hotelería }(\mathrm{h})\end{array}$ & $\begin{array}{r}* * \\
1,604 \\
0,771 \\
0,683 \\
1,604 \\
1,600\end{array}$ & $\begin{array}{r}* * * \\
0,297 \\
0,341 * * \\
-0,684 * * * \\
0,547 * * * \\
-0,010\end{array}$ & \\
\hline
\end{tabular}


Tabla 3. (continuación)

\begin{tabular}{|c|c|c|c|}
\hline & $\begin{array}{c}\text { Pobreza } \\
\text { más grave } \\
\text { Coef. BETA }\end{array}$ & $\begin{array}{c}\text { Salario/ } \\
\text { hora bajo } \\
\text { Coef. BETA }\end{array}$ & $\begin{array}{l}\text { Pobre } \\
\text { por hogar } \\
\text { Coef. BETA }\end{array}$ \\
\hline $\begin{array}{l}\text { - Transporte y comunicaciones (i) } \\
\text { - Intermediación financiera (j) } \\
\text { - Act. Inmobiliarias; serv empresariales (k) } \\
\text { - admón.. Pública (l) } \\
\text { - Educación (m) } \\
\text { - Actividades sanitarias y Serv.sociales (n) } \\
\text { - Servicios personales y de limpieza (o+p+q) }\end{array}$ & $\begin{array}{r}0,258 \\
1,180 \\
1,212 \\
-1,265 \\
-14,344 \\
0,854 \\
1,526\end{array}$ & $\begin{array}{r}0,194 \\
-1,189 * * \\
0,418 * * \\
-1,045^{* * *} \\
-0,033 \\
0,302 \\
0,946 * * *\end{array}$ & \\
\hline $\begin{array}{l}\text { Tamaño del centro de trabajo (Ref. NS-NC) } \\
\text { - Una persona } \\
\text { - de } 2 \text { a } 5 \\
\text { - de } 6 \text { a } 10 \\
\text { - de } 11 \text { a } 19 \\
\text { - de } 20 \text { a } 49 \\
\text { - más de } 49 \text { personas } \\
\text { - no sabe pero más de } 10\end{array}$ & $\begin{array}{r}* * * \\
1,446 * * * \\
0,432 * * \\
0,262 \\
-0,215 \\
-0,178 \\
-0,986 * * * \\
-0,510\end{array}$ & $\begin{array}{r}* * * \\
0,929 * * * \\
0,723 * * * \\
0,280 * * \\
-0,191 \\
-0,748^{* * * *} \\
-0,735 * * * \\
-0,359\end{array}$ & $\begin{array}{r}* * * \\
0,491 * * \\
0,113 \\
0,104 \\
-0,130 \\
-0,060 \\
-0,595 * * * \\
0,224\end{array}$ \\
\hline Contrato fijo (Ref. contrato temporal) & $-0,534 * * *$ & $-0,261 * * *$ & $-0,209 * * *$ \\
\hline Supervisa & $-0,497 * * *$ & $-0,340 * * *$ & $-0,189 * *$ \\
\hline Horas semana & $0,079 * * *$ & $0,079 * * *$ & $-0,042 * * *$ \\
\hline Número de años en trabajo remunerado & & $-0,053 * * *$ & \\
\hline Edad a la que empezó a trabajar & & $-0,042 * * *$ & \\
\hline Meses NO ocupado & & $0,136 * * *$ & \\
\hline $\begin{array}{l}\text { Cambió de trabajo el año de la renta (Ref. NS-NC) } \\
\text { - Sí } \\
\text { - No }\end{array}$ & & $\begin{array}{r}* * * \\
-0,581 * * * \\
-0,103\end{array}$ & $\begin{array}{r}* * \\
0,520^{*} \\
0,147\end{array}$ \\
\hline $\begin{array}{l}\text { CCAA*** no se reflejan los coeficientes } \\
\text { Tamaño de hábitat (Ref. Zona poco poblada) } \\
\text { - Zona muy poblada } \\
\text { - Zona media }\end{array}$ & & $\begin{array}{r}* * * \\
-0,119 \\
0,265 * * *\end{array}$ & \\
\hline $\begin{array}{l}\text { Constante } \\
\text { TOTAL N = } 9.752\end{array}$ & $-7,659$ & $-7,126$ & 40,977 \\
\hline-2 Log Likelihood & 928,887 & 3303,099 & 2725,939 \\
\hline
\end{tabular}

Niveles de significación: * $p<0,1000 ; * * p<0,0500 ; * * * p<0,0100$

El segundo perfil está constituido por el hogar monoparental donde la mujer es la sustentadora principal y hay hijos dependientes. Esta situación estará asociada no sólo a las cargas familiares, sino a los menores sueldos que consiguen las mujeres en el mercado de trabajo y su elevada proporción entre los trabajadores con salarios bajos (Asplud y Persson, 2000: 55).

Por su parte, el perfil de los trabajadores con salarios bajos y que no viven en hogares pobres que plantea la literatura es asimismo doble: uno estaría formado 
por mujeres casadas y el otro por jóvenes de uno u otro sexo no emancipados. En todo caso el elemento que les une es el hecho de que en sus hogares se reciben más salarios que el suyo propio. Aunque, por supuesto las aportaciones al hogar de estos salarios bajos son un elemento clave para apartar a la familia de la pobreza, como demuestra Nolan (1998).

Por último, el perfil de los asalariados que no reciben ingresos bajos por su trabajo pero cuya familia les aboca a la situación de pobreza se espera que se diferencie de las situaciones de pobreza más grave sobre todo en las características del empleo: estos no serán los propios de los empleos de peor calidad. Además, la influencia de las estructuras domésticas será fundamental, caracterizándose por la presencia de dependientes y la baja intensidad laboral.

\section{Situación de salario/hora bajo y hogar pobre}

Las características personales y de convivencia de aquellos asalariados en la situación más grave de pobreza se ajustan perfectamente a los dos perfiles planteados como hipótesis. El factor convivencial más explicativo del modelo es la intensidad laboral del hogar que entra a matizar el modo de convivencia. Por ello parece claro que las dos formas familiares con mayor riesgo de este tipo de pobreza son las familias monoparentales y las de único proveedor con hijos dependientes. Teniendo en cuenta el carácter acumulativo de los coeficientes, se ha de destacar la preocupante situación del primer tipo de hogares, las familias monoparentales, especialmente cuando el adulto responsable es una mujer.

Por otra parte, este es el único modelo en el que ha resultado de cierta significación la variable «cuidado de los hijos»; sin embargo su influencia no es tan directa como cabría considerar, pues podríamos pensar que aquellas familias que están en riesgo de pobreza lo están en parte por no poder dedicar tiempo al mercado de trabajo, ya que se encargan personalmente del cuidado de sus menores. Como se aprecia en la tabla, la influencia es negativa, es decir, las probabilidades de estar en la situación de pobreza más grave disminuyen a medida que aumenta el número de horas de cuidado de los hijos. Este resultado nos permitiría plantear como hipótesis explicativa que en las prioridades de uso del tiempo, obtener un nivel suficiente de ingresos está por delante del cuidado personal de los hijos.

Las características de los empleos, aunque importantes, parecen tener menos influencia en esta situación que las variables familiares, ya que sólo la estabilidad en el trabajo (contrato indefinido), el tamaño de las empresas, las horas trabajadas a la semana y si el trabajo tiene o no funciones de mando constituyen factores asociados a la pobreza más extrema. Aquí, poseer un contrato indefinido, que el trabajo tenga funciones de mando y pertenecer en una empresa con una plantilla superior a los 49 trabajadores alejan al individuo de tal situación, mientras que estar empleado en una empresa pequeña favorece la escasez de recursos económicos tanto individuales como familiares. El comportamiento de la variable horas de trabajo a la semana sugiere que estos trabajadores se ven obligados a 
trabajar un mayor número de horas, dada la baja cuantía del salario/hora, y por ello la variable presenta un coeficiente de signo positivo. Cabe destacar asimismo que los recursos formativos del trabajador han sido excluidos del modelo por no lograr suficiente significación estadística.

\section{Situación de salario/hora bajo y hogar no pobre}

Respecto al perfil de los trabajadores con salarios hora bajos cuyas características del hogar les alejan de la pobreza, ha resultado relevante el sexo y el tipo de convivencia. En concreto, tienen mayores probabilidades de estar en esta situación por un lado las mujeres que, aunque reciben pocos ingresos por su trabajo remunerado, no están en situación de pobreza por pertenecer a un hogar en el que hay otro sueldo; y por otro los jóvenes de uno u otro sexo no emancipados, pues conviven con más de dos adultos en el mismo hogar. Obviamente, al estar analizando aquellos casos en los que el asalariado con bajos ingresos tiene una familia que le aleja del riesgo de pobreza, la situación convivencial con menores probabilidades de estar en esta situación es la de la familia monoparental, pues es imposible que se produzca el efecto salvador de la familia.

Como era de esperar, los recursos formativos y las características de los empleos poseen un importante poder explicativo en la percepción de bajos salarios aunque el hogar no sea pobre. El comportamiento de estas variables resulta acorde con los resultados obtenidos en otras investigaciones mencionadas en este artículo. Así, poseer estudios universitarios disminuye la probabilidad de percibir un salario/hora por debajo del umbral de riesgo. La ocupación, que constituye una variable muy relacionada con la formación del trabajador, se encuentra muy asociada a los asalariados con rentas bajas del trabajo. Así, las ocupaciones no manuales presentan un coeficiente de signo negativo, en concreto las categorías de profesionales y técnicos y de técnicos de apoyo. Por el contrario, es en las ocupaciones manuales donde se concentran las rentas más bajas y en las que requieren menores cualificaciones para desarrollar las tareas del puesto: la categoría de trabajadores no cualificados. Asimismo, las ocupaciones con funciones de mando presentan un coeficiente negativo y muy significativo.

También se observa una importante relación con determinadas ramas de actividad. Son los sectores de servicios personales y de limpieza en los que se concentra en mayor grado este grupo de trabajadores. También destacan, con signo positivo, el comercio, las actividades inmobiliarias y la industria. Por el contrario, es muy poco probable ser pobre por el salario, aunque no por el hogar, si se trabaja en la construcción, la administración o en la rama de intermediación financiera. Junto a la rama de actividad destacan otras características del empleo como el tamaño de la empresa: los asalariados con bajos ingresos cuyas características del hogar les salvan de la pobreza se concentran en las empresas de pequeño tamaño, hasta 10 trabajadores, mientras que las grandes y medianas presentan una asociación negativa y estadísticamente significativa. Al igual que

EMPIRIA. Revista de Metodología de Ciencias Sociales. N. ${ }^{\text {14 }}$, julio-dicembre, 2007, pp. 41-67. ISSN: $1139-5737$ 
ocurría en el caso de la pobreza extrema, la baja cuantía del salario/hora incide en el mayor número de horas de actividad laboral que desarrollan estos trabajadores.

Ciertas características de la historia laboral del trabajador constituyen también factores explicativos. La experiencia laboral medida a través del número de años que se ha estado trabajando protege al individuo de la percepción de bajos salarios. También haber experimentado una menor rotación laboral, ya que no haber cambiado de empleo en el año de la renta evita la pertenencia a este colectivo, al igual que poseer un contrato indefinido. La edad a la que se ha entrado en la ocupación constituye otra variable significativa; el signo de su coeficiente indica que cuanto menos joven se inicia la actividad laboral menor es la probabilidad de ser pobre por el salario. Finalmente, las situaciones de inactividad (meses que se ha estado no ocupado en el año de la renta) favorecen la percepción de bajos salarios en estos trabajadores cuyas características del hogar les salvan de la pobreza.

\section{Situación de salario/hora no bajo y hogar pobre}

Si nos referimos a la tercera situación, la de aquellos que aún teniendo salarios por encima del umbral de riesgo están en situación de pobreza familiar, sus características son completamente congruentes con las hipótesis iniciales. En primer lugar, la intensidad laboral del hogar es la variable más explicativa para alejar a un asalariado de esta situación, y con un coeficiente muy elevado. El otro elemento explicativo es la existencia de hijos dependientes, ya que los menores aumentan las probabilidades de que el hogar sea pobre, mientras que en aquellas formas de convivencia en las que no hay menores y hay dos adultos o más las probabilidades son significativamente negativas.

Los asalariados que viven solos tienen también ciertas probabilidades de caer en esta situación. Esto nos está indicando que se trata de individuos con un salario/hora por encima del umbral de riesgo pero tienen una dedicación laboral al año menor a la estándar (todo el año a tiempo completo), y por ello los ingresos del hogar anuales se sitúan por debajo del umbral de pobreza. En cualquier caso se trata de una situación minoritaria.

Por último, el número de variables de tipo laboral que resultan significativas es reducido. Sólo favorece la entrada a esta situación la rotación laboral (haber cambiado de empleo en el año de la renta). Protegen al asalariado de este tipo de pobreza la pertenencia a una empresa de mediano y gran tamaño (más de 49 trabajadores), si el empleo tiene funciones de mando y si el contrato es indefinido. Además los recursos formativos del individuo no parecen afectar a la entrada en esta situación de pobreza familiar. La influencia negativa de las horas trabajadas a la semana es producto de la unidad temporal en la construcción de los indicadores. La pobreza por hogar se mide por los ingresos anuales, de forma que si se han trabajado pocas horas a la semana estos ingresos serán escasos aunque el sa- 
lario/hora sea alto. En otras palabras, se está recogiendo la pobreza del hogar, y ésta depende de la intensidad laboral (de la familia del asalariado y del propio asalariado).

\section{CONCLUSIONES}

Este artículo parte de la premisa de que en el fenómeno de los trabajadores pobres intervienen dos dimensiones que hay que tener en cuenta a la hora de emprender su análisis; por un lado, la cuantía del salario del trabajador; por otro, los ingresos y estructura de sus hogares. Se trata de dos dimensiones cuya interrelación hay que estudiar conjuntamente si se quiere obtener un conocimiento más profundo y perfilado del fenómeno en cuestión, y que a su vez pueden manifestarse de forma independiente. Así, en España según la ECV un 9,6\% de los asalariados perciben un salario que se sitúa por debajo del $60 \%$ de la mediana del salario/hora general. De ellos el 18,3\% viven en un hogar pobre. Por su parte, un $6,8 \%$ de los asalariados viven en un hogar que se sitúa por debajo del umbral de riesgo de pobreza. De este grupo de trabajadores, sólo el 25,7\% perciben bajos salarios. Estos resultados indican que la mayor parte de los trabajadores que tienen un salario bajo no son pobres, ya que sus hogares no lo son, y la mayoría de los trabajadores que viven en hogares pobres no perciben salarios bajos. La situación más grave de pobreza, aquella en la que coincide tanto un bajo salario como la pobreza del hogar afecta al 1,8\% de los asalariados.

Las características de los empleos y los recursos formativos del trabajador constituyen aspectos especialmente relevantes en la explicación de la obtención de bajos salarios, aunque el hogar no sea pobre. Los bajos salarios se concentran en los asalariados con escasos recursos formativos, con una menor experiencia laboral y en las categorías más bajas de la jerarquía ocupacional: los trabajadores manuales no cualificados. También se percibe su concentración en determinadas ramas de actividad -fundamentalmente en las ramas de servicios personales y de limpieza y en el comercio-, así como en las empresas de pequeño tamaño.

Por otra parte, encontramos algunos factores de tipo familiar que protegen a los trabajadores con sueldos bajos de caer en la pobreza. En concreto, los que tienen mayores probabilidades de encontrarse en esta situación (salario bajo y hogar no pobre) son los jóvenes no emancipados de uno y otro sexo y las mujeres que conviven con su pareja.

Con relación a las otras dos situaciones de pobreza analizadas en el artículo, las variables formativas y laborales pierden significatividad ante las características de la estructura familiar. Los factores que abocan a la pobreza son siempre la baja intensidad laboral del hogar y la presencia de dependientes, aunque se observan interesantes diferencias entre las dos situaciones. La pobreza más grave, aquella que tiene lugar cuando el salario propio es bajo y no se cuenta con el apoyo familiar, es eminentemente femenina, sobre todo está protagonizada por 
las mujeres cabezas de familia de hogares monoparentales. La pobreza producto exclusivamente de las características del hogar (los salarios no son bajos) depende mucho más de la intensidad laboral, tanto del hogar como del propio asalariado, y de la presencia de dependientes. Parece una situación más temporal de pobreza, producto del momento del ciclo vital familiar.

Pese a la menor influencia de las características de los empleos, no obstante, cabe destacar que, en todas las situaciones de pobreza contempladas, trabajar en una mediana o gran empresa, que el trabajo incorpore funciones de mando y poseer un contrato indefinido protegen al individuo de la percepción de bajos salarios y de la pobreza del hogar. Por el contrario, incrementan el riesgo pertenecer a una empresa de pequeño tamaño, el carácter temporal de los empleos y la rotación laboral. Estos resultados sugieren la existencia de una segmentación del mercado de trabajo, de tal manera que los empleos propios del mercado de trabajo secundario, con una elevada rotación, inseguridad y pocas posibilidades de carrera laboral tienen mayores probabilidades de ser ocupados por familias pobres

En el artículo también se ha demostrado la enorme importancia de la intensidad laboral del hogar a la hora de alejar a una familia de la pobreza. En este sentido, parece que se convierte en vital el acceso de las mujeres al empleo, sobre todo para aquellas economías familiares más necesitadas en las que ese otro sueldo puede alejarlas de la pobreza. Pero ante esto, cabría preguntarse: ¿hay que aumentar los empleos de bajos salarios? La respuesta no es fácil, pues aunque aumentase la intensidad laboral de la familia y con ello disminuyese la pobreza del hogar, tal medida podría tener otros efectos negativos. Uno de ellos es la continuidad de la discriminación laboral femenina, ya que si en mercados regulados la diferencia salarial entre hombres y mujeres en trabajos que requieren la misma cualificación es alta, si aumentan los trabajos de baja calidad se acentuará todavía más la diferencia salarial, o al menos no se reduciría. Tal efecto podría agravar la situación de las familias monoparentales, que no tienen la posibilidad de obtener ingresos de otros miembros.

\section{BIBLIOGRAFÍA}

Arai, M.; Asplund, R. y Barth, E. (1998). «Low Pay, A Matter of Occupation» en R. Asplund, P. J. Sloane y I. Theodossiou (eds) Low Pay and Earnings Mobility in Europe, Aldershot: Edward Elgar, pp. 139-161.

Asplund, R. y Persson, I. (2000). «Low Pay - A Special Affliction of Women» en M. Gregory; W. Salverda y S. Bazen (eds) Labour Market Inequalities. Problems and Policies of Low-Wage Employment in International Perspective, Oxford: Oxford University Press, pp. 53-81.

BARDONE, L. y GUIO, A. C. (2005). «In-Work Poverty. New commonly agreed indicators at the EU level» Eurostat Statistics in focus, Population and Social Conditions (5/2005) Catalogo número: KS-NK-05-005-EN-N. 
BAZEN, S., Gregory, M. y SAlverda, W. B. (eds.) (1998). Low-wage Employment in Europe, Aldershot: Edward Elgar.

CARABAÑA, J. (1994). «La constante homogamia educativa», Economía y Sociedad, 11: 43-65.

Contini, B.; FilipPI, M. y Villosio, C. (1998). «Earnings Mobility in the Italian Economy» en R. Asplund, P. J. Sloane and I. Theodossiou (eds) Low Pay and Earninigs Mobility in Europe, Aldershot: Edward Elgar, pp. 15-31.

CRAYPO, C. y CORMIER, D. (2000). «Job Restructuring as a Determinant of Wage Inequality and Working-Poor Households», Journal of Economic Issues, XXXIV(1): 21-42.

DenNis, I. (2002). «Medir la dicha y la miseria», Revista Fuentes Estadísticas, 63. (http://www.ine.es/revistas/fuentes/Numero63/paginas/7-8.htm)

EIRO (2002). «Low-wage workers and the "working poor"» European Foundation for the Improvement of Living and Working Conditions, European Industrial Relations Observatory On-line (http://www.eiro.eurofound.ie/)

ERIKSSON, T. (1998). «Long-Term Earnings Mobility of Low-Paid Workers in Finland» en R. Asplund, P. J. Sloane y I. Theodossiou (eds.) Low Pay and Earnings Mobility in Europe, Aldershot: Edward Elgar, pp. 32-46.

FreEMAN, R. B. y SCHETTKAT, R. (2002). «Low-Wage Services: Interpreting the US-German Difference» en M. Gregory; W. Salverda y S. Bazen (eds) Labour Market Inequalities. Problems and Policies of Low-Wage Employment in International Perspective, Oxford: Oxford University Press, pp. 157-176.

Gardiner, K. y Millar, J. (2006). «How Low-Paid Employees Avoid Poverty»: An Analysis by Family Type and Household Structure, Journal of Social Policy, 35(3): 351-369.

Gregory, M. y JuKES, R. (1998). «The Effects of Unemployment on Future Earnings: Low-Paid Men in Bretain 1984-94», en R. Asplund, P. J. Sloane y I. Theodossiou (eds) Low Pay and Earnings Mobility in Europe, Aldershot: Edward Elgar, pp. 165184.

Gregory, M.; SAlverda, W. y BAZEN, S. (eds.) (2000). Labour Markets Inequalities. Problems and Policies of Low-wage Employment in International Perspective, Oxford, Oxford University Press.

INE (2004). «Encuesta de Estructura Salarial 2002. Resultados Definitivos» Notas de Prensa, 16 de noviembre de 2004. Madrid, INE (http://www.ine.es/prensa/np347.pdf)

INE (2005). «Encuesta de Condiciones de Vida. Año 2004. Principales resultados». Notas de Prensa, 5 de diciembre de 2005.

JEnkins, S. (1991). «Poverty Measurement and the Within Household Distribution: Agenda for Action», The Journal of Social Policy, 20(4): 457-483.

Jordan, B.; James, S.; Kay, H. y Redley, M., (1991). Trapped in Poverty: Labourmarket Decisions in Low-income Households, London: Routledge.

Keese, M.; Puymoyen, A. y Swaim, P. (1998). «The Incidente and Dynamics of LowPaid Employment in OECD Countries» en R. Asplund, P. J. Sloane y I. Theodossiou (eds) Low Pay and Earnings Mobility in Europe, Aldershot: Edward Elgar, pp. 223265. 
Layte, R. and Whelan, C. T. (2003). «Moving in and out of poverty», European Societies, 5(2): 167-192.

Levitan, S. A.; Gallo, F. y Shapiro, I. (1993). Working but poor: America's contradiction. Baltimore, The Johns Hopkins University Press. (1st. ed. 1987).

LuCIFORA, C. (1998). «Working Poor? An analysis Of Low-Wage Employment in Italy» in R. Asplund, P. J. Sloane y I. Theodossiou (eds), Low Pay and Earnings Mobility in Europe, Aldershot: Edward Elgar, pp. 185-208.

MarX, I. y Verbist, G. (1999). «Low-Paid Work and Poverty: A Cross-Country Perspective», en S. Bazen, M. Gregory and W. B. Salverda, (eds) Low-Wage Employment in Europe, Aldershot: Edward Elgar, pp. 63-82.

Nolan (1998). Low Pay in Ireland, Vol. II of the Report of the National Minimum Wage. Commission, Dublin, Stationery Office.

Nolan, B. y MarX, I. (2000). «Low Pay and Household Poverty» en M. Gregory; W. Salverda y S. Bazen (eds) Labour Market Inequalities. Problems and Policies of LowWage Employment in International Perspective, Oxford: Oxford University Press, pp. 100-119.

Peña-Casas, R. y LatTA, M. (2004). Working poor in the European Union. Luxemburg, Office for Official Publications of the European Communities.

Sloane, P. y Theodossiou, I. (2002). «Earnings Mobility of the Low Paid», en M. Gregory; W. Salverda y S. Bazen (eds) Labour Market Inequalities. Problems and Policies of Low-Wage Employment in International Perspective, Oxford: Oxford University Press, pp. 82-99.

Stocks, J.; DíAz, C. y Halleröd, B. (ed.) (2007). Modern Couples Sharing Money, Sharing Life, Hampshire: Palgrave MacMillan.

Whelan, C. T.; Layte, R.; Maître, B. y Nolan, B. (2000). «An analysis of the 1994 and 1995 waves of the European Community Household Panel Survey», European Societies, 2(4): 505-531. 


\section{RESUMEN}

La lucha contra la pobreza ha venido siendo uno de los objetivos principales de toda agenda política. En este contexto, en las últimas décadas se ha puesto en evidencia una categoría social que ha trastocado el concepto de pobreza tradicional y ha introducido un nuevo debate muy relacionado con la calidad de los empleos, tal como se muestra en la cumbre europea de Laeken: los trabajadores pobres. Para este colectivo se han venido barajando varias soluciones ise aumentan los empleos de baja calidad con el objetivo de reducir la pobreza? O por el contrario, ¿la pobreza deriva de esa baja calidad? Para clarificar este debate, el presente artículo analiza los distintos factores familiares y laborales que se hallan asociados a diferentes tipos de pobreza: la situación de aquellos trabajadores en los que coinciden los bajos salarios y la pobreza del hogar, la de aquellos cuyo salario se sitúa por debajo del umbral de riesgo pero cuya familia les aleja de la pobreza, y, por último, la situación de los trabajadores que aun no percibiendo un bajo salario las características de sus hogares les avocan a la pobreza. La fuente de datos utilizada es la Encuesta de Condiciones de Vida referida a España. Los resultados muestran importantes diferencias en el comportamiento de las variables familiares y laborales según las distintas situaciones de pobreza. Dos resultados son asimismo destacables; por un lado, la enorme importancia de la intensidad laboral del hogar a la hora de alejar a una familia de la pobreza; por otro, la existencia de una segmentación en el mercado de trabajo de manera que los peores empleos están siendo desempeñados por las familias más pobres.

\section{PALABRAS CLAVE}

Trabajadores pobres, salarios bajos, mercado de trabajo, Encuesta de Condiciones de Vida.

\section{ABSTRACT}

In recent years, a new social category has come to the fore, which has transformed the concept of traditional poverty: the category of the working poor. This has introduced a new debate, very much centred on job quality, as became evident at the European Laeken summit. Several solutions have been discussed in relation to this category: Should we increase the number of low-quality jobs so as to reduce poverty? Or conversely, does poverty result from this low quality? In order to clarify this debate, the present article analyzes the different occupational and household factors associated with various types of poverty: the situation of workers characterized by low earnings and household poverty; those whose earnings are under the risk threshold, but whose families shield them from poverty; and finally, the situation of workers who do not receive low wages, but 
whose household characteristics lead them to poverty. The data source used are the European Statistics on Income and Living Conditions referring to Spain. The results show important differences in the behaviour of occupational and household variables, depending on the divergent poverty situations. Two other results should also be highlighted: on the one hand, the important extent to which household work intensity protects the family from falling into poverty; on the other hand, the existence of labour market segmentation, which has the effect that the worst jobs are reserved for the poorest families.

\section{KEYWORDS}

Working poor, low-pay, labour market, EU-SILC. 